\begin{tabular}{|c|c|c|}
\hline UFJ/UFG & $\begin{array}{c}\text { GEOAMBIENTE ON-LINE } \\
\text { Revista Eletrônica do Curso de Geografia } \\
\text { Graduação e Pós-Graduação } \\
\text { Htpp://www.revistas.ufg.br/geoambiente } \\
\text { Jataí-GO | n } 36 \text { | Jan-Abr/2020 }\end{array}$ & $\begin{array}{l}\text { :GEO } \\
\text { ¿AMBIENTE } \\
\text { ISSN } 1679-9860\end{array}$ \\
\hline
\end{tabular}

\title{
GEODIVERSIDADE, GEOSSÍTIOS E GEOCONSERVAÇÃO NO POVOADO SACO MONTE BELO, MUNICÍPIO DE PIRACURUCA (PI)
}

Marineldo de Brito Lima ${ }^{1}$, Mayara Jordana de Castro Sousa ${ }^{2}$, Jessica Karollayne Carvalho Nascimento $^{2}$, Francílio de Amorim dos Santos $^{3}$

(1 - Secretaria de Estado da Educação do Piauí, Graduado em Geografia, marineldobrito@gmail.com; https://orcid.org/0000-0002-1841-5795, 2 - Universidade Federal do Piauí, Graduanda em Geografia, castromayara99@gmail.com; https://orcid.org/0000-00029045-6268, karolljessica1@gmail.com; https://orcid.org/0000-0001-8978-6756, 4 - Instituto Federal do Piauí, Doutor em Geografia, francilio.amorim@ifpi.edu.br, https://orcid.org/0000$\underline{0002-0415-6673)}$

Resumo: O semiárido do Nordeste do Brasil (NEB) apresenta exuberantes paisagens e que demandam realização de estudos para conhecimento de suas feições e dinâmica, como forma de promover ações de geoconservação. Nesse sentido, o presente estudo buscou identificar e caracterizar área com relevante Geodiversidade e potencial uso para o geoturismo, bem como mensurar o seu Valor Turístico (Vtur) no setor Sudoeste do município de Piracuruca, localizado no Norte do Estado do Piauí. Para tal fim, utilizou-se trabalho de campo associado ao uso de arquivos cartográficos e instrumentos técnicos para realização do estudo. $\mathrm{O}$ afloramento rochoso na localidade Caldeirão situa-se sobre os arenitos da Formação Cabeças e tem como principal característica as feições de relevo ruiniforme. Destaca-se a ocorrência de outros elementos, a saber: poligonação, com variadas formas geométricas; processo de oxidação; presença de túneis anastomosados, de diâmetros variados; formação de marmitas de dissolução, distribuídas por diversos pontos e com várias profundidades e diâmetros; ocorrência de pináculos nos topos dos afloramentos rochosos; grafismos rupestres, que constituem relevantes testemunhos da história humana; cobertura vegetal ligada à Caatinga Arbustiva conservada. Fica evidente o grande potencial que o geossítio Caldeirão apresenta em relação ao geoturismo, particularmente o turismo sertanejo. Logo, o uso dessa área de forma econômica deve estar associado a estudos prévios para elaboração de planejamentos e identificação da capacidade de suporte do geossítio.

Artigo recebido para publicação em 14 de Março de 2019

Artigo aprovado para publicação em 24 de Abril de 2020 


\begin{tabular}{|c|c|c|}
\hline UFJ/UFG & $\begin{array}{c}\text { GEOAMBIENTE ON-LINE } \\
\text { Revista Eletrônica do Curso de Geografia } \\
\text { Graduação e Pós-Graduação } \\
\text { Htpp://www.revistas.ufg.br/geoambiente } \\
\text { Jataí-GO|n } 36 \text { | Jan-Abr/2020 }\end{array}$ & $\begin{array}{l}\text { :GEO } \\
\text { ¿AMBIENTE } \\
\text { ISSN } 1679-9860\end{array}$ \\
\hline
\end{tabular}

Palavras-chave: Geossítio Caldeirão. Feições ruiniformes. Conservação.

\section{GEODIVERSITY, GEOSYTES AND GEOCONSERVATION IN THE POVOADO SACO MONTE BELO, MUNICIPALITY OF PIRACURUCA (PI)}

Abstract: The semi-arid region of Northeastern Brazil (NEB) presents exuberant landscapes and demands the realization of studies to know their features and dynamics, as a way to promote geoconservation actions. In this sense, the present study sought to identify and characterize an area with relevant Geodiversity and potential use for geotourism, as well as to measure its Tourism Value (Vtur) in the Southwest sector of the Piracuruca municipality, located in the North of the State of Piauí. For this purpose, we used fieldwork associated with the use of cartographic files and technical instruments to carry out the study. The rocky outcrop in the Caldeirão locality is located on the sandstone of the Cabeças Formation and has as its main characteristic features of ruiniform relief. It stands out the occurrence of other elements, namely: polygon, with varied geometric forms; oxidation process; presence of anastomosed tunnels of varying diameters; formation of dissolving kettles, distributed over several points and with various depths and diameters; occurrence of pinnacles on the tops of rocky outcrops; cave paintings, which constitute relevant testimonies of human history; vegetation cover linked to the conserved Shrub Caatinga. It is evident the great potential that the Caldeirão geosite presents in relation to the geotourism, particularly the sertanejo tourism. Therefore, the use of this area in an economical way should be associated with previous studies to elaborate the planning and identification of the support capacity of the geosite.

Key words: Caldeirão Geosite. Ruiniform features. Conservation.

\section{GEODIVERSIDAD, GEOSIDADES Y GEOCONSERVACIÓN EN LAS PERSONAS SACO MONTE BELO, MUNICIPIO DE PIRACURUCA (PI)}

Resumen: La región semiárida del Noreste de Brasil (NEB) tiene paisajes exuberantes que requieren estudios para comprender sus características y dinámicas, como una forma de promover acciones de geoconservación. En este sentido, el presente estudio buscó identificar y caracterizar un área con Geodiversidad relevante y uso potencial para el geoturismo, así como medir su Valor Turístico (Vtur) en el sector suroeste del municipio de Piracuruca, ubicado en el norte del estado de Piauí. Para este propósito, el trabajo de campo asociado con el uso de archivos cartográficos e instrumentos técnicos se utilizó para llevar a cabo el 


\begin{tabular}{|c|c|c|}
\hline UFJ/UFG & $\begin{array}{c}\text { GEOAMBIENTE ON-LINE } \\
\text { Revista Eletrônica do Curso de Geografia } \\
\text { Graduação e Pós-Graduação } \\
\text { Htpp://www.revistas.ufg.br/geoambiente } \\
\text { Jataí-GO | n } 36 \text { | Jan-Abr/2020 }\end{array}$ & $\begin{array}{l}\text { :GEO } \\
\text { :GEMIENTE } \\
\text { ISSN } 1679-9860\end{array}$ \\
\hline
\end{tabular}

estudio. El afloramiento rocoso en la ciudad de Caldeirão se encuentra en las areniscas de la Formación Cabeças y tiene las características principales del relieve ruiniforme. La aparición de otros elementos, a saber: polígono, con formas geométricas variadas; proceso de oxidación; presencia de túneles anastomosados, de diámetros variables; formación de recipientes de disolución, distribuidos en varios puntos y con diferentes profundidades y diámetros; aparición de pináculos en las cimas de afloramientos rocosos; pinturas rupestres, que son testimonios relevantes de la historia humana; cubierta vegetal vinculada al arbusto conservado Caatinga. Es evidente el gran potencial que presenta el geositio de Caldeirão en relación con el geoturismo, particularmente el turismo de sertanejo. Por lo tanto, el uso de esta área de manera económica debe estar asociado con estudios previos para la elaboración de planes e identificación de la capacidad de soporte del geositio.

Palabras clave: Geosita Caldeirão. Rasgos ruiniformes. Conservación

\section{INTRODUÇÃO}

O mapeamento da Geodiversidade, notadamente em áreas com uso potencial para o desenvolvimento de geoturismo, é sumamente importante. Nesse contexto, insere-se o semiárido do Nordeste do Brasil (NEB), que exibe distintas e exuberantes paisagens, particularmente ligadas ao seu aspecto geomorfológico. Desse modo, são áreas que necessitam de estudos para conhecimento de suas feições e dinâmica, como instrumento fundamental para elaboração e implantação de estratégias de geoconservação.

Destaca-se que a Royal Society for Nature Conservation do Reino Unido classificou a Geodiversidade como sendo a variedade de ambientes geológicos, fenômenos e processos ativos que são produto da formação de paisagens, rochas, minerais, fósseis, solos. Desse modo, constituem-se depósitos superficiais e, por conseguinte, substrato para o desenvolvimento da vida na Terra (STANLEY, 2000).

Os termos Geodiversidade, geoconservação e geoturismo geram varias divergências que estão associadas principalmente ao caráter amplo ou mesmo restrito, quando se trata da definição de cada um desses termos. Nesse sentido, Gray (2013) destaca que o termo Geodiversidade está ligado à variedade natural (diversidade) de elementos geológicos (rochas, minerais e fósseis), geomorfológicos (formas de relevo, topografia e processos físicos), do solo e hidrológico. Ressalta-se, ainda, que o referido termo pode ser conceituado como a 


\begin{tabular}{|c|c|c|}
\hline UFJ/UFG & $\begin{array}{c}\text { GEOAMBIENTE ON-LINE } \\
\text { Revista Eletrônica do Curso de Geografia } \\
\text { Graduação e Pós-Graduação } \\
\text { Htpp://www.revistas.ufg.br/geoambiente } \\
\text { Jataí-GO | n } 36 \text { | Jan-Abr/2020 }\end{array}$ & $\begin{array}{l}\text { :GEO } \\
\text { 亡́AMBIENTE } \\
\text { ISSN } 1679-9860\end{array}$ \\
\hline
\end{tabular}

autobiografia do planeta Terra, posto que dela possam ser adquiridas informações sobre a evolução do planeta produzidas por ela mesma (MEDEIROS et al., 2011).

Outra possibilidade de entendimento para o conceito de Geodiversidade foi proposta pelo Serviço Geológico do Brasil (CPRM), que conceitua esse termo da seguinte forma:

[...] variação natural (diversidade) da geologia (rochas minerais, fósseis, estruturas), geomorfologia (formas e processos) e solos. Essa variedade de ambientes geológicos, fenômenos e processos faz com que essas rochas, minerais, fósseis e solos sejam o substrato para a vida na Terra. Isso inclui suas relações, propriedades, interpretações e sistemas que se inter-relacionam com a paisagem, as pessoas e culturas (PFALTZGRAFF; TORRES, 2010, p.11).

Por sua vez, a geoconservação por ser compreendida como uma forma de preservação da Geodiversidade, particularmente daquela que exibe significativos aspectos geológicos, geomorfológicos e pedológicos, possibilitando a evolução natural desses aspectos e processos (SHARPLES, 2002). Nessa ótica, a geoconservação está ligada as ações empregadas no sentido de preservar a Geodiversidade, promover a gestão do Patrimônio Geológico e a manutenção dos processos naturais a ele associados.

Nesse cenário, Brilha (2005) define Patrimônio como o conjunto de geossítios de uma determinada área, ou seja, são locais onde ocorre um ou mais elementos da Geodiversidade com particular valor do ponto de vista científico, pedagógico, cultural e turístico. Por sua vez, o conceito de geoconservação diz respeito a um novo paradigma ou corrente de pensamento que está ligado ao meio natural e sua conservação (PEREIRA et al., 2009).

Nesse contexto, cabe inserir o conceito de geoturismo, que diz respeito a uma atividade turística dirigida às características geográficas de um local, partindo do meio natural local, passando pela estética e patrimônio ambiental e cultural, chegando ao bem-estar de povos residentes nos locais visitados. Desse modo, Seabra (2014) distingue o Turismo Sertanejo como uma forma de lazer baseada na paisagem natural, no patrimônio cultural e no desenvolvimento social e econômico do Sertão do Brasil. Para o mesmo autor, o Sertão compreende o hinterland do país, ou seja, as terras continentais distantes do mar. Diga-se, também, que de acordo com Medeiros e Oliveira (2011), o geoturismo está relacionado a um segmento do turismo que tem como principal atrativo os elementos da Geodiversidade, particularmente do Geopatrimônio.

Nesse cenário, Pereira (2006) aborda que os valores para avaliação do patrimônio geomorfológico são cinco, a saber: científico, estético, econômico e cultural. No entanto, 


\begin{tabular}{|c|c|c|}
\hline UFJ/UFG & $\begin{array}{c}\text { GEOAMBIENTE ON-LINE } \\
\text { Revista Eletrônica do Curso de Geografia } \\
\text { Graduação e Pós-Graduação } \\
\text { Htpp://www.revistas.ufg.br/geoambiente } \\
\text { Jataí-GO | n } 36 \text { | Jan-Abr/2020 }\end{array}$ & $\begin{array}{l}\text { :GEO } \\
\text { 亡́AMBIENTE } \\
\text { ISSN } 1679-9860\end{array}$ \\
\hline
\end{tabular}

ressalta-se serem várias as metodologias para avaliação, ou seja, cada área tem sua importância e dependendo da sua potencialidade pode ter valor turístico e/ou didático. Por outro lado, os parâmetros ligados ao valor turístico são: acessibilidade, aspectos estético, estado de conservação, condições de observação e associação com elementos culturais.

Nessa perspectiva, considerou-se relevante a realização do estudo a partir da demanda por conhecerem-se áreas de expressiva beleza cênica (geossítios) e, por conseguinte, elaborarse ações de geoconservação. Dessa maneira, utilizou-se como procedimento o trabalho de campo associado ao uso de arquivos cartográficos e alguns instrumentos técnicos (GPS Portátil Garnim Etrex 20x e aparelho smartphone) para mapeamento da Geodiversidade no setor Sudoeste do município de Piracuruca, estado do Piauí.

Nessa ótica, o geógráfo como pesquisador do espaco geográfico deve estudar os fenômenos que perpassam aquele ambiente, notadamente seus aspectos naturais. Dessa maneira, o presente estudo teve como objetivos identificar e caracterizar área com relevante Geodiversidade e potencial uso para o geoturimso, bem como mensurar seu Valor Turístico (Vtur), no setor Sudoeste do município de Piracuruca, localiza no Norte do Estado do Piauí.

\section{MATERIAIS E MÉTODOS}

\subsection{Localização e caracterização da área em estudo}

A pesquisa foi desenvolvida no município de Piracuruca, localizado na parte Norte do Estado do Piauí. Sua sede municipal está situada a $60 \mathrm{~m}$ de altitude e sua posição geográfica está localizada às coordenadas geográficas $03^{\circ} 55^{\prime} 41^{\prime \prime} \mathrm{S}$ e $41^{\circ} 42^{\prime} 33^{\prime \prime} \mathrm{W}$. Esse município possui os seguintes limites municipais: ao norte, Caraúbas do Piauí e Cocal; ao sul, Brasileira; a leste, Cocal dos Alves e São João da Fronteira; a oeste, Caraúbas do Piauí, São José do Divino e Batalha (IBGE 2015), conforme está representado na Figura 1.

O geossítio Caldeirão é um afloramento da Formação Cabeças, datado do Devoniano Médio, sua formação está associada à presença de arenitos de diferentes cores claras, brancos, cinza-amarelados chegando a vermelho, médios a grosseiro, conglomerático e muito pouco argilosos, de aspecto maciço devido sua estratificação espessa e comumente cruzada bem desenvolvida. Ressalta-se que em alguns locais os arenitos exibem intercalações de siltitos e arenitos finos, laminados de cores claras (BAPTISTA, 1981; CPRM, 2006a; 2006b). Ressalta- 


\begin{tabular}{|c|c|c|}
\hline UFJ/UFG & $\begin{array}{c}\text { GEOAMBIENTE ON-LINE } \\
\text { Revista Eletrônica do Curso de Geografia } \\
\text { Graduação e Pós-Graduação } \\
\text { Htpp://www.revistas.ufg.br/geoambiente } \\
\text { Jataí-GO | n } 36 \text { | Jan-Abr/2020 }\end{array}$ & $\begin{array}{l}\text { :GEO } \\
\text { ISSN } 1679-9860\end{array}$ \\
\hline
\end{tabular}

se que uma melhor caracterização será realizada ao longo da discussão acerca de cada geossítio identificado.

Figura 1 - Localização do geossítio Caldeirão, localizado no povoado Saco Monte Belo, que pertencente ao município de Piracuruca (PI).

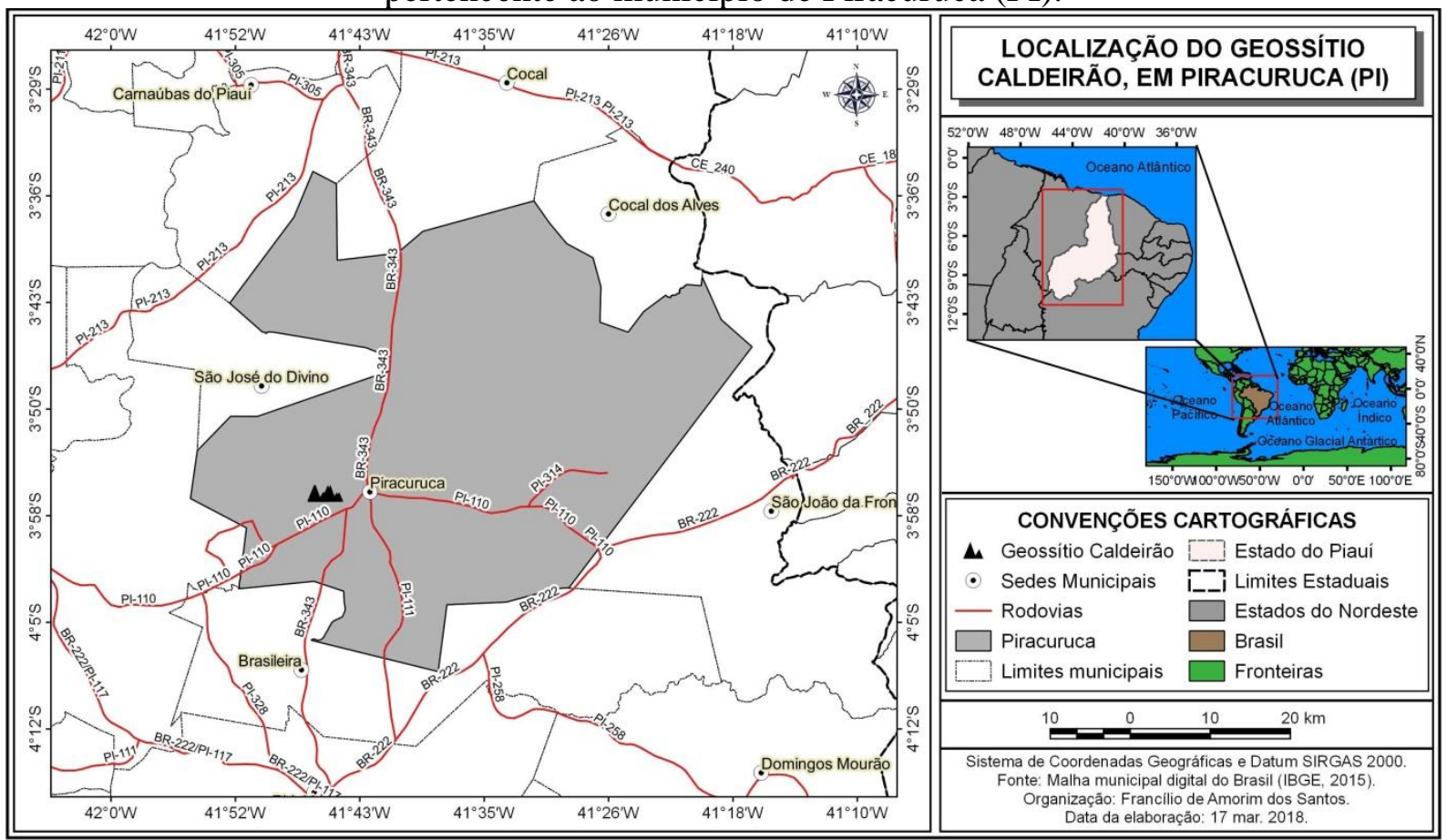

Fonte: Malha municipal digital do Brasil (IBGE, 2015).

\subsection{Procedimentos metodológicos}

O estudo ora apresentado apresenta caráter descritivo, pois buscou descrever as características de determinada população ou fenômeno (GIL, 2002), particularmente ligado aos aspectos da Geodiversidade, no setor Sudoeste do município de Piracuruca. Ressalta-se que para operacionalizar tal estudo foi necessário realizar pesquisa de campo que, conforme asseguram Prodanov e Freitas (2013), constitui instrumento para aquisição de informações e/ou conhecimentos acerca de um problema.

Inicialmente, procedeu-se a um levantamento bibliográfico e cartográfico, onde se buscou aprofundar os conhecimentos teóricos e práticos sobre da temática abordada e área estudada, principalmente acerca dos aspectos biofísicos da área estudada. Nesse sentido, foram adquiridos e utilizados os seguintes arquivos cartográficos: Mapa de Geodiversidade do Piauí, arquivo vetorial, em escala 1:1.000.000 (CPRM, 2006a); Mapa de solos da Folha 


\begin{tabular}{|c|c|c|}
\hline UFJ/UFG & $\begin{array}{c}\text { GEOAMBIENTE ON-LINE } \\
\text { Revista Eletrônica do Curso de Geografia } \\
\text { Graduação e Pós-Graduação } \\
\text { Htpp://www.revistas.ufg.br/geoambiente } \\
\text { Jataí-GO | n 36 | Jan-Abr/2020 }\end{array}$ & $\begin{array}{l}\text { :GEO } \\
\text { ISSN } 1679-9860 \\
\text { ISMBIENTE }\end{array}$ \\
\hline
\end{tabular}

SB.24, arquivo vetorial, em escala 1:250.000 (INDE, 2014); Mapa Geológico do Estado do Piauí, arquivo formato pdf, em escala 1:1.000.000 (CPRM, 2006b).

Em seguida procedeu-se à atividade de campo no povoado Saco Monte Belo, que foi realizada no dia 09 de fevereiro de 2018, utilizando-se como via de acesso a PI-110. Ressaltase que por meio do trabalho de campo foram identificados 13 (treze) pontos relacionados à área do geossítio Caldeirão, onde foram anotadas as suas respectivas coordenadas geográficas e registros fotográficos. Ressalta-se que o local onde estão situados os geossítios identificados, com altitude média de 74 metros, fica no setor Sudoeste do município de Piracuruca. Para a atividade de campo foram utilizados os seguintes instrumentos: GPS Portátil Garnim Etrex 20x e aparelho smartphone, respectivamente, para obtenção das coordenadas geográficas e realização de registros fotográficos da área estudada.

Após obtenção dos dados cartográfico, bibliográfico e dos obtidos em pesquisas de campo, foi realizada uma mensuração do Valor Turístico (Vtur) do geossítio, para isso foi utilizada a metodologia proposta por Pereira (2010). O Vtur consolida informações que permitem uma avaliação da realidade atual, referente à utilização turística do geossítio. Desse modo, destaca-se que Pereira (2010) emprega 5 parâmetros na classificação do Vtur, conforme está expresso no Quadro 1. 


\begin{tabular}{|c|c|c|}
\hline UFJ/UFG & $\begin{array}{c}\text { GEOAMBIENTE ON-LINE } \\
\text { Revista Eletrônica do Curso de Geografia } \\
\text { Graduação e Pós-Graduação } \\
\text { Htpp://www.revistas.ufg.br/geoambiente } \\
\text { Jataí-GO|n } 36 \text { | Jan-Abr/2020 }\end{array}$ & $\begin{array}{l}\text { :GEO } \\
\text { ISAMBIENTE } \\
\text { ISSN } 1679-9860\end{array}$ \\
\hline
\end{tabular}

Quadro 1 - Parâmetros de classificação do Valor Turístico (Vtur).

\begin{tabular}{|c|c|c|c|c|c|}
\hline Parâmetros & 0 & 1 & 2 & 3 & 4 \\
\hline Aspecto estético & $\begin{array}{l}\text { Geossítio sem } \\
\text { qualquer } \\
\text { relevância } \\
\text { estética, } \\
\text { inserido em } \\
\text { local sem } \\
\text { qualquer apelo } \\
\text { cênico } \\
\end{array}$ & - & $\begin{array}{c}\text { Geossítio } \\
\text { inserido em } \\
\text { local aprazível } \\
\text { ou } \\
\text { dotado de } \\
\text { algum elemento } \\
\text { com apelo } \\
\text { estético }\end{array}$ & - & $\begin{array}{l}\text { Geossítio dotado de } \\
\text { espetacularidade } \\
\text { estética } \\
\text { e inserido em local } \\
\text { aprazível, dotado } \\
\text { de apelo } \\
\text { cênico }\end{array}$ \\
\hline Acessibilidade & $\begin{array}{c}\text { Acessível a } \\
\text { partir de trilha } \\
\text { com mais de } 5 \\
\text { km } \\
\text { de extensão }\end{array}$ & $\begin{array}{l}\text { Acessível a } \\
\text { partir de } \\
\text { trilha com } 2 \\
\text { a } 5 \mathrm{~km} \mathrm{de} \\
\text { extensão }\end{array}$ & $\begin{array}{l}\text { Acessível a } \\
\text { partir de } \\
\text { estradas não } \\
\text { asfaltadas } \\
\text { e trilha com } \\
\text { menos de } 2 \mathrm{~km} \\
\text { de extensão }\end{array}$ & $\begin{array}{l}\text { Acessível a } \\
\text { partir de } \\
\text { estradas } \\
\text { asfaltadas e } \\
\text { trilha com } \\
\text { menos de } 2 \\
\text { km de } \\
\text { extensão }\end{array}$ & $\begin{array}{c}\text { Acessível } \\
\text { diretamente através } \\
\text { de estradas } \\
\text { principais (federais } \\
\text { ou estaduais) } \\
\text { asfaltadas }\end{array}$ \\
\hline $\begin{array}{l}\text { Presença de } \\
\text { infraestrutura }\end{array}$ & $\begin{array}{l}\text { Ausência de } \\
\text { qualquer } \\
\text { infraestrutura }\end{array}$ & - & $\begin{array}{c}\text { Dotado de } \\
\text { infraestrutura } \\
\text { rudimentar, } \\
\text { mas } \\
\text { que sirvam de } \\
\text { apoio ao } \\
\text { visitante } \\
\end{array}$ & - & $\begin{array}{c}\text { Dotado de } \\
\text { infraestrutura plena } \\
\text { que prestem } \\
\text { todo o apoio ao } \\
\text { visitante }\end{array}$ \\
\hline $\begin{array}{l}\text { Existência de } \\
\text { utilização em } \\
\quad \text { curso }\end{array}$ & $\begin{array}{c}\text { Geossítio sem } \\
\text { qualquer uso } \\
\text { atual }\end{array}$ & $\begin{array}{l}\text { Geossítio } \\
\text { com alguma } \\
\text { taxa de } \\
\text { visitação, } \\
\text { porém ainda } \\
\text { incipiente }\end{array}$ & - & $\begin{array}{l}\text { Geossítio com } \\
\text { alta taxa de } \\
\text { visitação, } \\
\text { porém } \\
\text { sem } \\
\text { mecanismo de } \\
\text { controle de } \\
\text { visitantes }\end{array}$ & $\begin{array}{c}\text { Geossítio com } \\
\text { elevada taxa de } \\
\text { visitação e } \\
\text { dotado medidas de } \\
\text { controle de } \\
\text { visitantes }\end{array}$ \\
\hline $\begin{array}{l}\text { Presença de } \\
\text { mecanismos de } \\
\text { controle de } \\
\text { visitantes }\end{array}$ & $\begin{array}{l}\text { Ausência de } \\
\text { qualquer tipo } \\
\text { de controle }\end{array}$ & - & $\begin{array}{l}\text { Existência de } \\
\text { um mecanismo } \\
\text { não sistemático } \\
\text { de controle, de } \\
\text { caráter ainda } \\
\text { incipiente }\end{array}$ & - & $\begin{array}{l}\text { Existência de } \\
\text { controle } \\
\text { sistemático e } \\
\text { eficiente } \\
\text { de visitantes } \\
\end{array}$ \\
\hline
\end{tabular}

Fonte: Pereira (2010).

\section{RESULTADOS E DISCUSSÃO}

O Afloramento rochoso denominado Caldeirão, está localizado em área sedimentar, possivelmente ligado aos depósitos colúvio-eluviais, que remontam a era Cenozoica e período Quaternário, tendo se formado há aproximadamente 1,75 milhões antes do presente. Ressalta- 


\begin{tabular}{|c|c|c|}
\hline UFJ/UFG & $\begin{array}{c}\text { GEOAMBIENTE ON-LINE } \\
\text { Revista Eletrônica do Curso de Geografia } \\
\text { Graduação e Pós-Graduação } \\
\text { Htpp://www.revistas.ufg.br/geoambiente } \\
\text { Jataí-GO | n } 36 \text { | Jan-Abr/2020 }\end{array}$ & $\begin{array}{l}\text { :GEO } \\
\text { 亡́AMBIENTE } \\
\text { ISSN } 1679-9860\end{array}$ \\
\hline
\end{tabular}

se que a área pesquisada está situada sobre a Formação Cabeças, cuja principal característica é a ocorrência de rochas de natureza sedimentar, principalmente de arenitos cuja gênese está associada a ambientes fluviais (CPRM, 2006).

No local é possível encontrar feições de relevo ruiniformes, que podem ser divididos em duas classes: modelado ruiniforme alto com mais de 10 metros de altura e modelado ruiniforme baixo com menos de 10 metros de altura (SANTOS, 2001). Cabe salientar que para Ab'Saber (1977), a topografia ruiniforme é uma feição morfológica encontrada em arenitos diaclasados, dotados de paredes e torres com os mais variados aspectos geométricos e, de acordo com Guerra e Guerra (1997), surgem por erosão diferencial.

\subsection{Caracterização do geossítio Saco Monte Belo}

No local pesquisado foi identificada a ocorrência do fenômeno de poligonação, que gera variadas formas geométricas, a exemplo de um monólito que pode ser observado na Figura 2. Para Mainguet (1972), a poligonação é oriunda da ação de desagregação granular, seguindo os planos de fratura existentes na rocha arenítica e que evidencia o padrão de arranjo poligonal das fraturas, o autor considera sua ocorrência frequente no arenito.

Figura 2 - Monólito, com mais de 5 metros de altura, exibindo efeitos de poligonação.

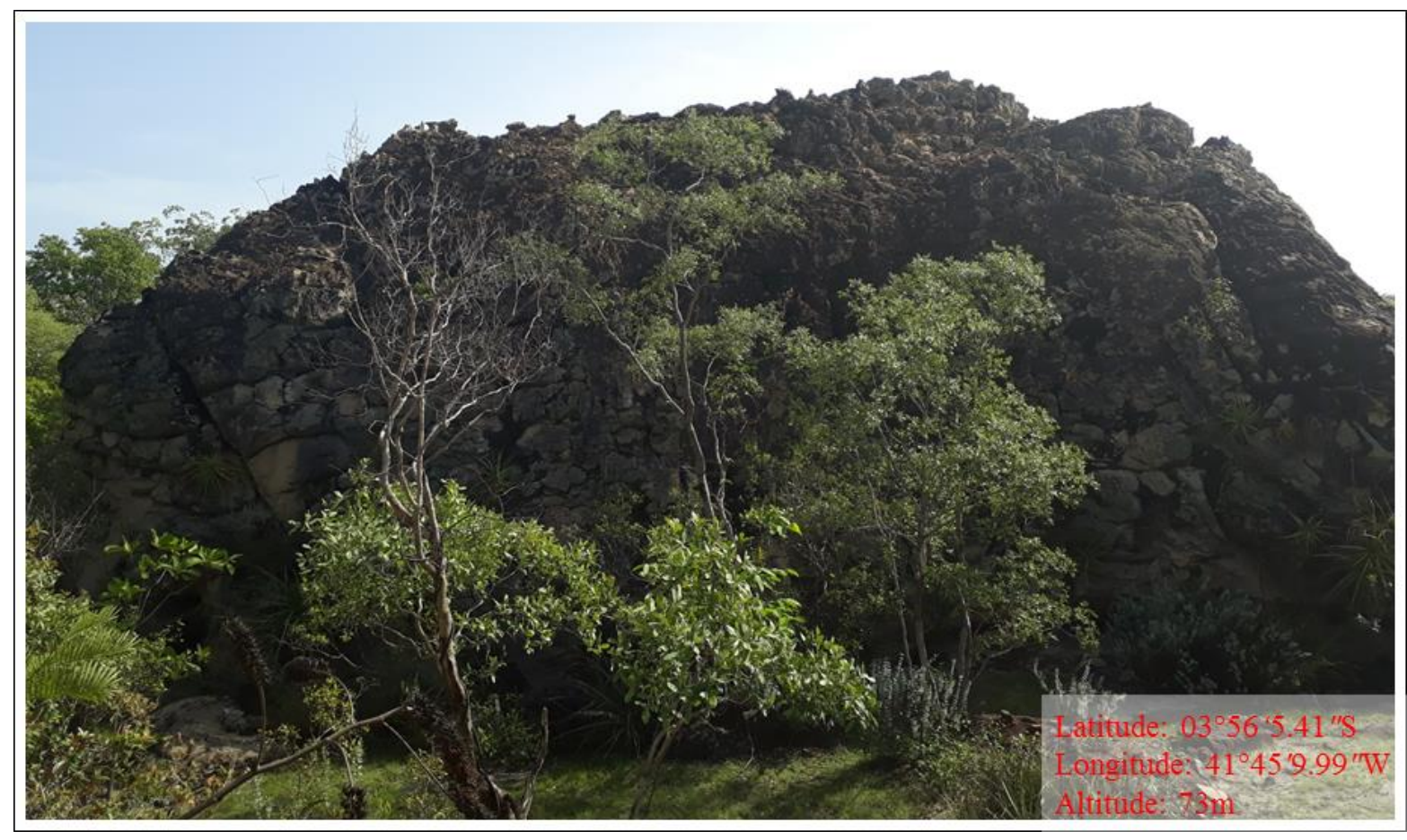

Fonte: Arquivo dos autores 


\begin{tabular}{|c|c|c|}
\hline UFJ/UFG & $\begin{array}{c}\text { GEOAMBIENTE ON-LINE } \\
\text { Revista Eletrônica do Curso de Geografia } \\
\text { Graduação e Pós-Graduação } \\
\text { Htpp://www.revistas.ufg.br/geoambiente } \\
\text { Jataí-GO | n } 36 \text { | Jan-Abr/2020 }\end{array}$ & $\begin{array}{l}\text { :GEO } \\
\text { 亡́AMBIENTE } \\
\text { ISSN } 1679-9860\end{array}$ \\
\hline
\end{tabular}

Durante as incursões até o geossítio Caldeirão, notou-se certa semelhança entre alguns modelados ruiniformes com os existentes no Parque Nacional Sete Cidades, particularmente a Figura 3A que apresenta um processo de poligonação semelhante ao monumento Tartaruga, presente na sexta cidade do referido Parque. A Figura 3B apresenta um monólito popularmente chamado de "Pedra do Love", bastante conhecido entre os moradores locais e tem essa denominação em virtude de alguns casais de jovens utilizarem-na como cenário romântico para tirar fotos.

Observa-se, ainda, que alguns monólitos apresentam rochas com tons escurecidos, fato este decorrente do processo de intemperismo químico via oxidação. Nesse cenário, destaca-se que o processo de decomposição dos minerais pela oxidação ocorre pela ação oxidante de $\mathrm{O}_{2}$ e $\mathrm{CO}_{2}$, dissolvidos na água - hidratados, óxidos, carbonatos, etc. Minerais contendo Fe, Mn, S e $\mathrm{Cu}$ são os mais susceptíveis a ocorrência do fenômeno de oxidação (MARANGON, 2009). Nesse contexto, Bigarella et al. (1994) destaca que devido o arenito possuir natureza quartzosa, isso permite a formação de couraças ferruginosas, permitindo aos óxidos de $\mathrm{Fe}$ depositarem-se ao redor dos grãos de quartzo ou crescer como concreções.

Figura 3 - Efeitos do processo de poligonação. Em A: Monumento "Pedra da Tartaruga", localizado no Parque Nacional de Sete Cidades (Piracuruca - PI); em B: Monólito denominado "Pedra do Love".

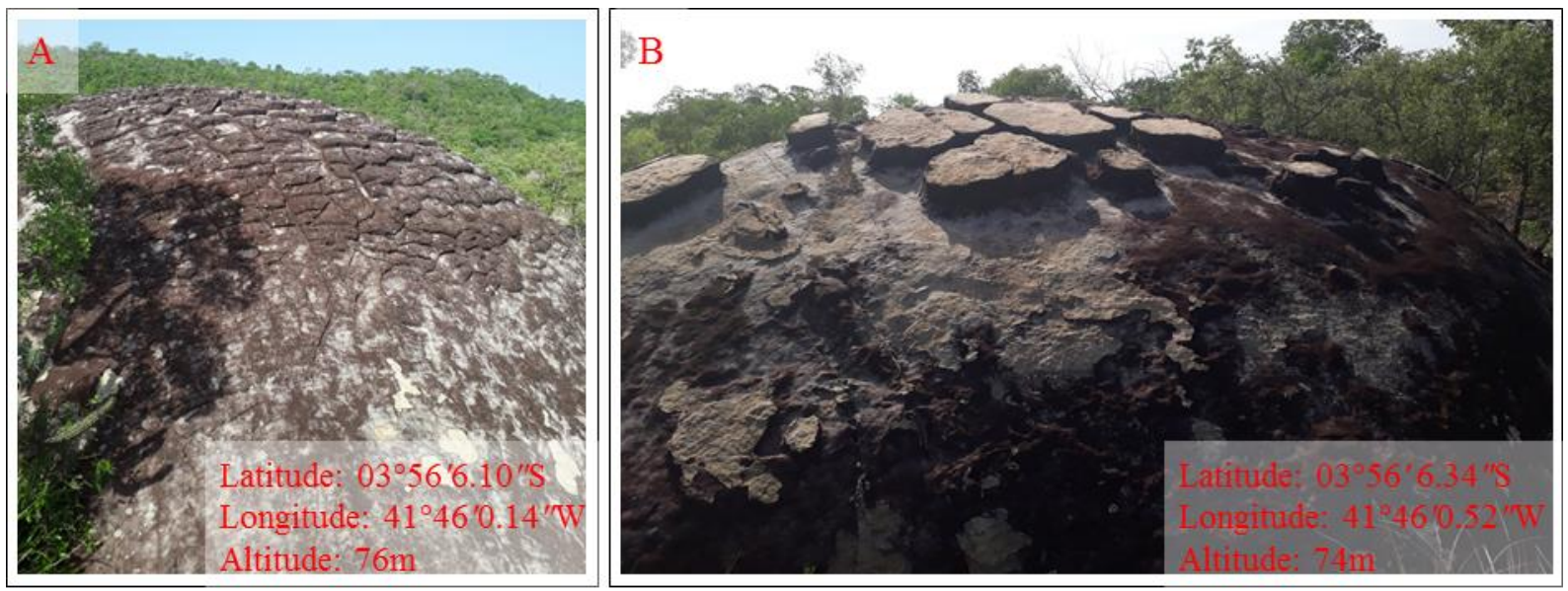

Fonte: Arquivo dos autores (2018).

Destaca-se, também, que há ocorrência de túneis anastomosados que, de acordo com Fortes (1996), caracterizam-se pela existência de orifícios numerosos em camadas individualizadas na superfície dos paredões rochosos, que se conectam e cujo tamanho pode variar entre 1 a $20 \mathrm{~cm}$, em sua maioria. No local há túneis anastomosados com considerável 


\begin{tabular}{|c|c|c|}
\hline UFJ/UFG & $\begin{array}{c}\text { GEOAMBIENTE ON-LINE } \\
\text { Revista Eletrônica do Curso de Geografia } \\
\text { Graduação e Pós-Graduação } \\
\text { Htpp://www.revistas.ufg.br/geoambiente } \\
\text { Jataí-GO | n 36 | Jan-Abr/2020 }\end{array}$ & $\begin{array}{l}\text { :GEO } \\
\text { ISSN } 1679-9860\end{array}$ \\
\hline
\end{tabular}

diâmetro para esse tipo de fenômeno (Figura 4), podendo sugerir que o fluxo de água existente ali, em algum momento no passado, possuía grande intensidade para resultar em tal intensidade desse processo erosivo no arenito.

Figura 4 - Túneis, com superfície exibindo várias perfurações.

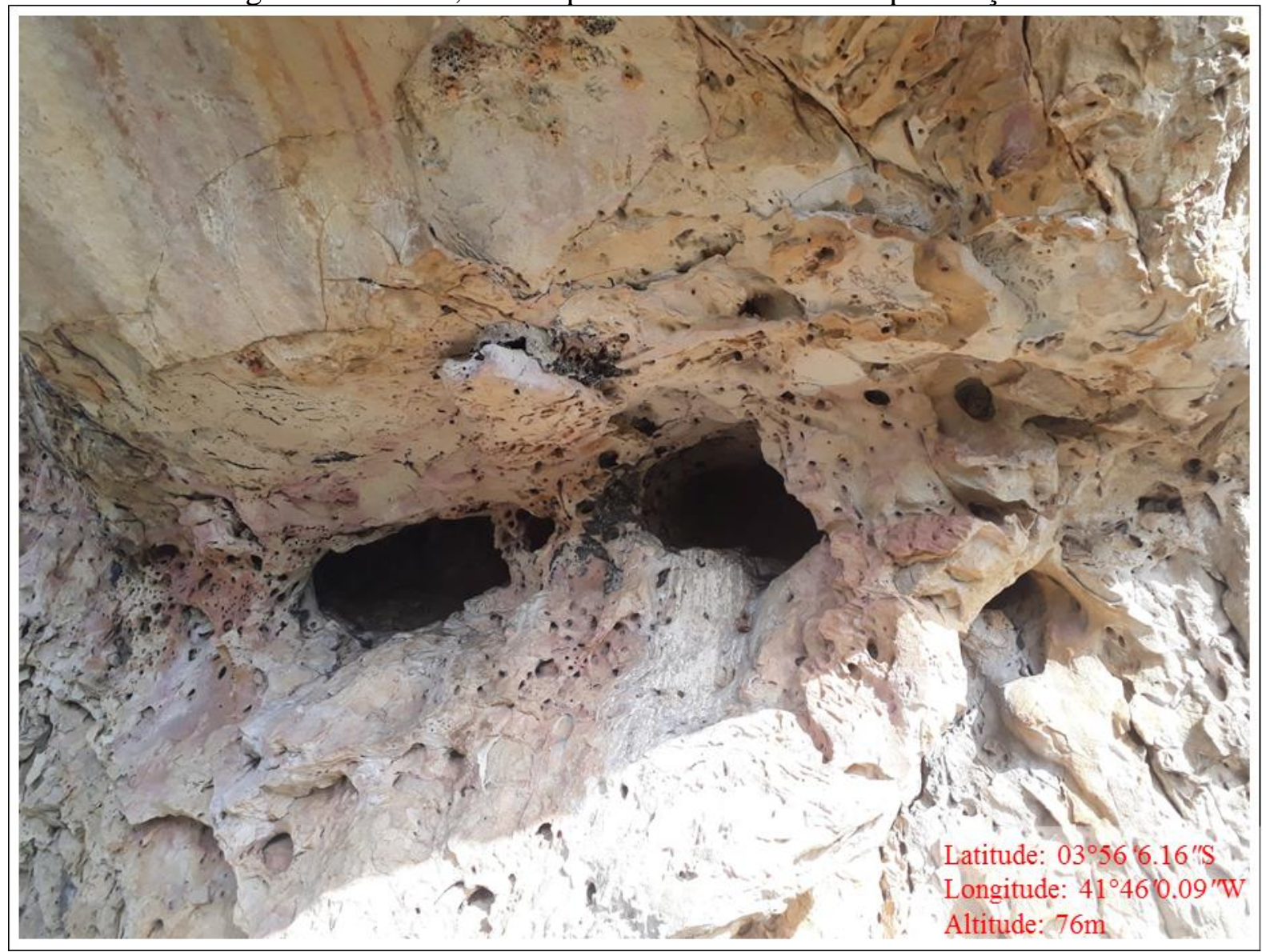

Fonte: Arquivo dos autores

Ainda, sobre os processos erosivos existentes no arenito do geossítio Caldeirão, tem-se a formação de marmitas de dissolução (Figura 5), que estão espalhadas por diferentes pontos e com distintas profundidades e diâmetros. Este fenômeno resulta da ação da água sobre a rocha arenítica em locais que apresentem um desnível, notadamente aquelas pertencentes da Formação Cabeças. Destaca-se que em determinadas época essas marmitas podem ser um atrativo turístico ao local, visto que algumas formam piscinas naturais, propiciando o banho em caso de criação de trilhas ecológicas ali. 


\begin{tabular}{|c|c|c|}
\hline UFJ/UFG & $\begin{array}{c}\text { GEOAMBIENTE ON-LINE } \\
\text { Revista Eletrônica do Curso de Geografia } \\
\text { Graduação e Pós-Graduação } \\
\text { Htpp://www.revistas.ufg.br/geoambiente } \\
\text { Jataí-GO | n 36 | Jan-Abr/2020 }\end{array}$ & $\begin{array}{l}\text { :GEO } \\
\text { ISSN } 1679-9860 \\
\text { ISMBIENTE }\end{array}$ \\
\hline
\end{tabular}

Figura 5 - Marmitas de dissolução, exibindo vários metros de diâmetro.

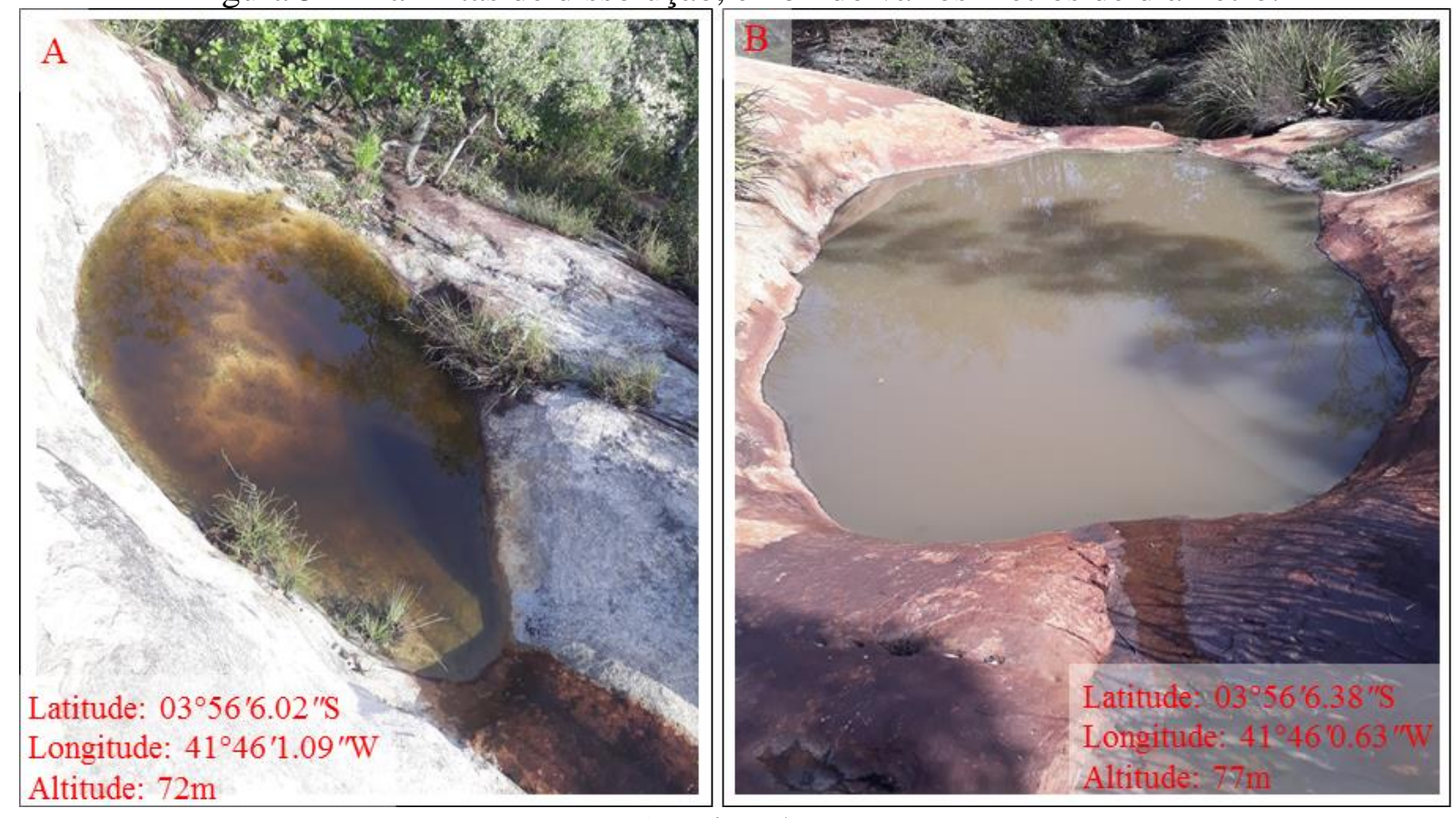

Fonte: Arquivo dos autores

Outro fenômeno recorrente na área pesquisada está associado à presença de pináculos, presentes nos topos dos afloramentos rochosos (Figura 6). Santos (2001) assevera que em relação a essas feições a superfície da rocha apresenta-se com pequenos ressaltos ondulados, retorcidos, contínuos ou em pequenas elevações isoladas e retorcidas. Essas feições constituem polígonos com topo fragmentados em pequenas torres semelhantes a diversos castelos, que apresentam cerca $8 \mathrm{~cm}$ de altura e em seu interior apresentam depressões.

No geossítio Caldeirão, para além do patrimônio geológico-geomorfológico, destacase há existência de importantes testemunhos da própria história humana. As pinturas rupestres existentes ali se configuram como importante marco de registro e deslocamento dos povos ancestrais. É possível visualizar diversas inscrições (Figura 7), algumas delas em bom estado de conservação, podendo servir de subsídio a futuros estudos sobre os comportamentos e a cultura dos povos que as produziram. 


\begin{tabular}{|c|c|c|}
\hline UFJ/UFG & $\begin{array}{c}\text { GEOAMBIENTE ON-LINE } \\
\text { Revista Eletrônica do Curso de Geografia } \\
\text { Graduação e Pós-Graduação } \\
\text { Htpp://www.revistas.ufg.br/geoambiente } \\
\text { Jataí-GO | n } 36 \text { | Jan-Abr/2020 }\end{array}$ & $\overbrace{\text { @GEO }}$ \\
\hline
\end{tabular}

Figura 6 - Formação de pináculos, onde se pode perceber o efeito poligonal.

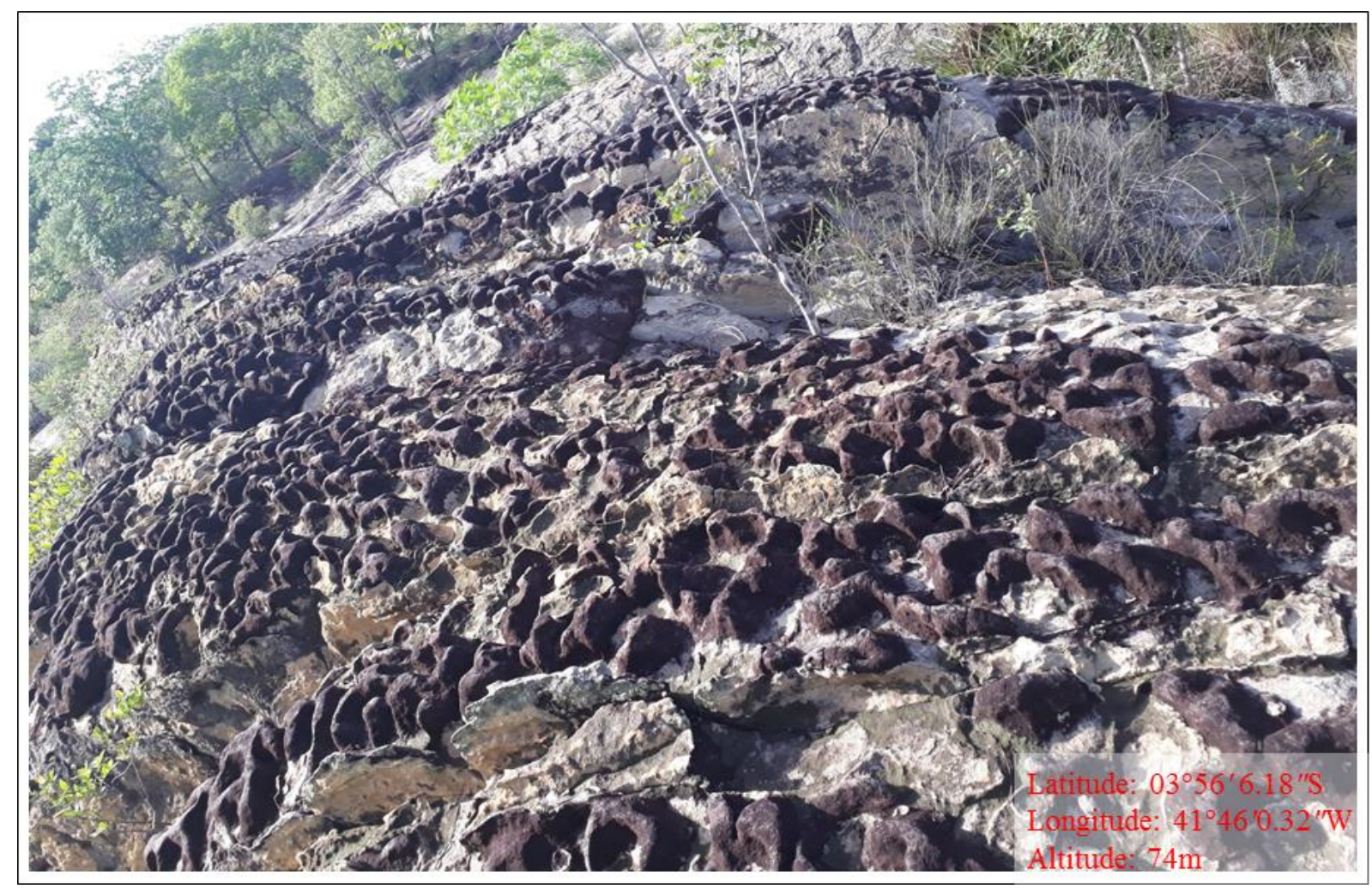

Fonte: Arquivo dos autores

Figura 7 - Pinturas rupestres com motivos geométricos.

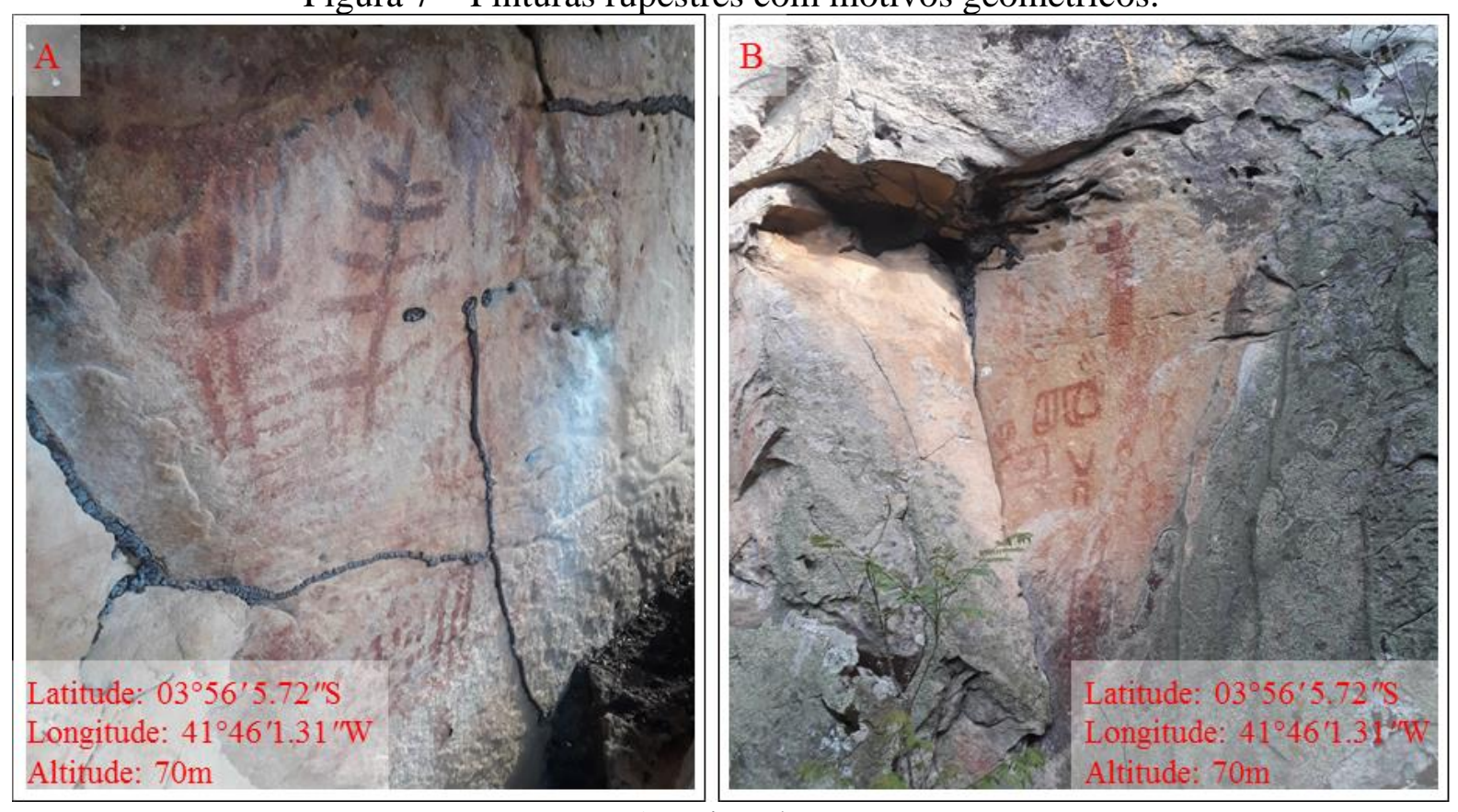

Fonte: Arquivo dos autores 


\begin{tabular}{|c|c|c|}
\hline UFJ/UFG & $\begin{array}{c}\text { GEOAMBIENTE ON-LINE } \\
\text { Revista Eletrônica do Curso de Geografia } \\
\text { Graduação e Pós-Graduação } \\
\text { Htpp://www.revistas.ufg.br/geoambiente } \\
\text { Jataí-GO | n } 36 \text { | Jan-Abr/2020 }\end{array}$ & $\begin{array}{l}\text { :GEO } \\
\text { 亡́AMBIENTE } \\
\text { ISSN } 1679-9860\end{array}$ \\
\hline
\end{tabular}

A composição vegetal do local está relacionada à Caatinga de porte Arbustivo (Figura 8), com presença de xerófilas e tropófilas, com predomínio de espécies caducifólias e, ainda, uma pequena quantidade de perenifólias. A vegetação no local está bem preservada, não se observando áreas degradadas no afloramento rochoso Caldeirão.

Figura 8 - Vista panorâmica do local, apresentando bom estado de conservação.

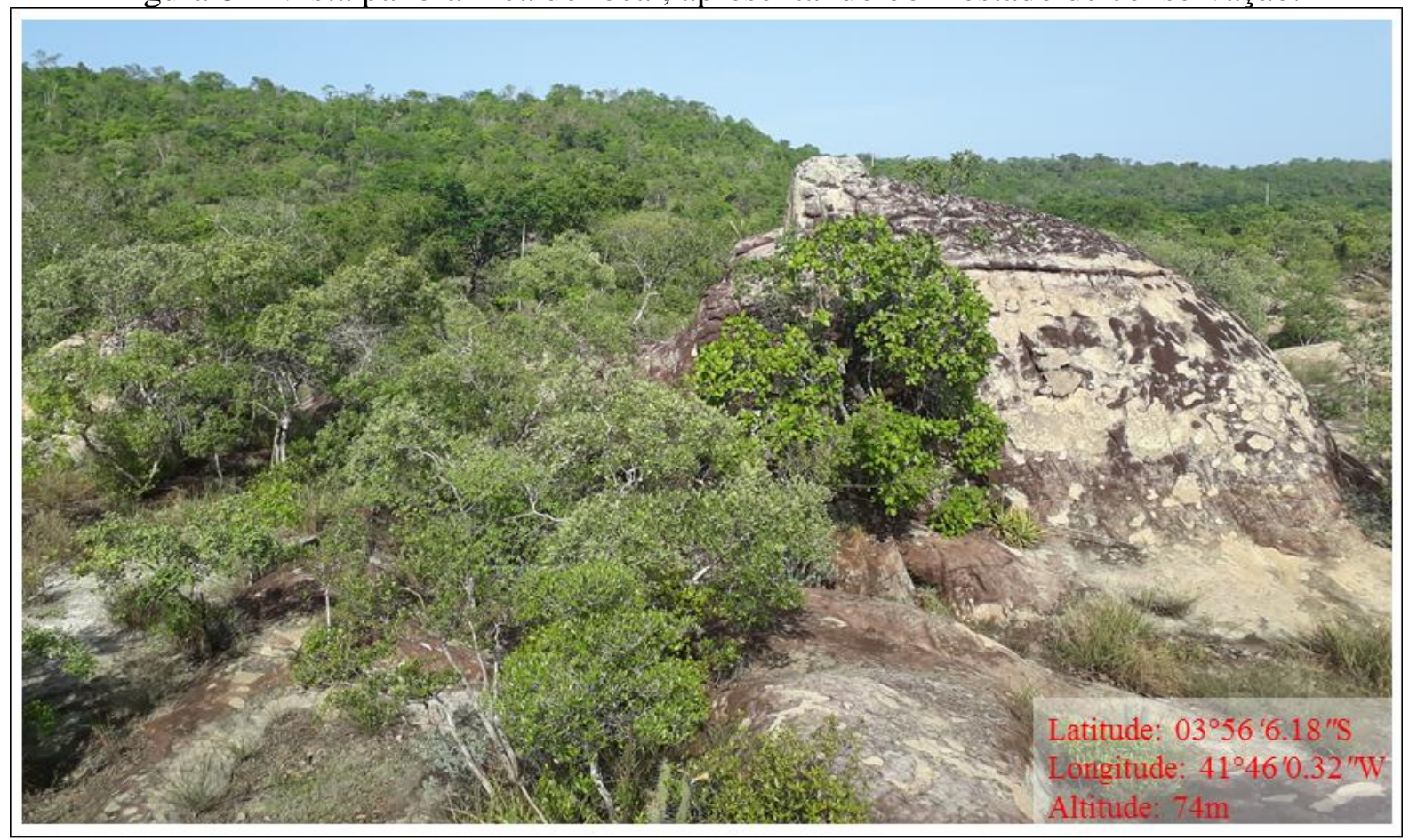

Fonte: Arquivo dos autores.

Frente o que foi apresentado, fica evidente o potencial do local pesquisado para o desenvolvimento do geoturismo em virtude de sua notável Geodiversidade. Diga-se, também, que se configura como um ponto de considerável potencial econômico e científico, visto que apresenta notável patrimônio geomorfológico e cultural, demandando estudos mais acurados, cujo foco deve estar alicerçado na geoconservação.

\subsection{Quantificação do valor turístico (Vtur)}

No Quadro 2 apresenta-se os valores atribuídos em cada parâmetro para o geossítio Saco Monte Belo, baseado na metodologia proposta por Pereira (2010). O local apresenta grande beleza cênica, no entanto a acessibilidade até o local é difícil e não há nenhum tipo de estrutura para facilitar o acesso de pessoas com dificuldades motoras ou para controlar os fluxos de imigrantes. 


\begin{tabular}{|c|c|c|}
\hline UFJ/UFG & $\begin{array}{c}\text { GEOAMBIENTE ON-LINE } \\
\text { Revista Eletrônica do Curso de Geografia } \\
\text { Graduação e Pós-Graduação } \\
\text { Htpp://www.revistas.ufg.br/geoambiente } \\
\text { Jataí-GO | n } 36 \text { | Jan-Abr/2020 }\end{array}$ & $\begin{array}{l}\text { :GEO } \\
\text { 亡́AMBIENTE } \\
\text { ISSN } 1679-9860\end{array}$ \\
\hline
\end{tabular}

Quadro 2 - Valores atribuídos a cada parâmetro.

\begin{tabular}{|c|c|}
\hline Parâmetros de cálculo do Valor Turístico (Vtur) & Nota atribuída \\
\hline Aspecto estético & 4 \\
\hline Acessibilidade & 3 \\
\hline Presença de infraestrutura & 0 \\
\hline Existência de utilização em curso & 0 \\
\hline Presença de mecanismo de controle de visitantes & $\mathbf{1 , 4}$ \\
\hline Média &
\end{tabular}

Fonte: Arquivo dos autores (2018).

O valor baixo adquirido pelo geossítio dá-se à pela inexistência de estrutura para acesso e deslocamento dentro do mesmo, caso houvesse um investimento privado ou público para estruturação e utilização turística do geossítio, é provável que o local apresentasse grande atratividade. Nesse cenário, destaca-se o estudo de Santos e Lima (2018), realizado no afloramento Mocozal e utilizou o Vtur, cuja média foi de 1,04, fato justificado pela inexistência de qualquer tipo de infraestrutura para acesso, controle ou utilização da geodiversidade identificada na pesquisa.

Reitera-se a necessidade de desenvolvimento de estratégias para conservação da área em questão. Pois, embora seu valor turístico tenha exibido baixo valor, a diversidade presente na área é de suma importância para o desenvolvimento local socioeconômico local e, ainda, entendimento da histórica dos povos antepassados que se utilizaram desse local, seja como ponto de passagem ou estabelecimento de moradia fixa. Desse modo, será possível melhorar os indicadores utilizados no estudo e implementar ações voltadas a sua geoconservação.

\section{CONCLUSÕES}

- O presente trabalho teve êxito em seu objetivo, visto que identificou e caracterizou a Geodiversidade existente na localidade Caldeirão, situada no município de Piracuruca. Fato este que deve contribuir para a construção do conhecimento científico sobre a temática na região Norte do Estado do Piauí. Nesse contexto, destaca-se que o local estudado apresenta distintas feições geomorfológicas, fruto da atuação principalmente da ação pluvial. Nesse sentido, cabe destacar o notável potencial da Geodiversidade local e a possibilidade de seu aproveitamento para o geoturismo. 


\begin{tabular}{|c|c|c|}
\hline UFJ/UFG & $\begin{array}{c}\text { GEOAMBIENTE ON-LINE } \\
\text { Revista Eletrônica do Curso de Geografia } \\
\text { Graduação e Pós-Graduação } \\
\text { Htpp://www.revistas.ufg.br/geoambiente } \\
\text { Jataí-GO | n } 36 \text { | Jan-Abr/2020 }\end{array}$ & $\begin{array}{l}\text { :GEO } \\
\text { ISSN } 1679-9860 \\
\text { ISAMBIENTE }\end{array}$ \\
\hline
\end{tabular}

- O trabalho corrobora o fato do descuido com a Geodiversidade dentro do município de Piracuruca, já constatado pelos presentes autores em outros ensaios acadêmicos. Ressalta-se que o geossítio Caldeirão apresenta claro potencial para o geoturismo, notadamente ligado ao turismo sertanejo. Tais práticas além de desenvolverem a economia local, auxiliam na geoconservação do mesmo por meio da sensibilização dos moradores do entorno e turistas que frequentem aquele ponto.

- O local pesquisado demanda futuros trabalhos, para a realização de uma análise mais aprofundada. Ressalta-se que é importante que a exploração do geoturismo no local seja pautada em estudos e planejamentos sobre a capacidade de suporte do geossítio, de forma a minimizar o impacto da atividade econômica sobre a notável Geodiversidade daquele ponto. Ratifica-se a relevância de pesquisas semelhantes a essa para construção de uma base de dados precisos e que permitam à gestão tomada de decisão de forma adequada, tomando como ponto de partida a geoconservação da riqueza presente no espaço geográfico local.

\section{REFERÊNCIAS}

BAPTISTA, E. M. DE C. Geomorfologia e Geodiversidade do litoral piauiense para fins de Geoconservação. Revista de Geociências do Nordeste, v. 2, p. 1250-1258, 27 out. 2016. ISSN: 2447-3359.

BIGARELLA, J.J.; BECKER, R.D.; SANTOS, G.F. Estrutura e origem das paisagens tropicais e subtropicais. Florianópolis: Ed. UFSC, 1994.

BRASIL. Ministério de Minas e Energias. Departamento Nacional de Produção Mineral. Projeto RADAM: levantamento dos recursos naturais, folha SB.23 Teresina. Rio de Janeiro. 1973. v.2.

BRILHA, J.B.R. Patrimônio geológico e geoconservação: a conservação da natureza na sua vertente geológica. São Paulo: Palimage editora, 2005. ISBN: 972-8575-90-4.

BRILHA, J.B.R.; PEREIRA D.; PEREIRA, P. Geodiversidade: valores e usos. Braga: Universidade do Minho, 2008. ISBN: 978-972-95255-6-8.

FORTES, F. P. Geologia de Sete Cidades. Teresina: Fundação Monsenhor Chaves, 1996.

GIL, A.C. Como elaborar projetos de pesquisa. - 4. Ed. - São Paulo: Atlas, 2002. ISBN 85224-3169-8. 


\begin{tabular}{|c|c|c|}
\hline UFJ/UFG & $\begin{array}{c}\text { GEOAMBIENTE ON-LINE } \\
\text { Revista Eletrônica do Curso de Geografia } \\
\text { Graduação e Pós-Graduação } \\
\text { Htpp://www.revistas.ufg.br/geoambiente } \\
\text { Jataí-GO | n 36 | Jan-Abr/2020 }\end{array}$ & $\begin{array}{l}\text { :GEO } \\
\text { ISSN } 1679-9860\end{array}$ \\
\hline
\end{tabular}

GRAY, M. Geodiversity: valuing and conserving abiotic nature. Chichester, England: John Wiley \& Sons Ltd, 2004. ISBN 0-470-84896-0 (PB).

Geodiversity: valuing and conserving abiotic nature: 2. ed. Chichester, England: John Wiley \& Sons, 2013. ISBN 13: 9780470742150.

GUERRA, A.T.; GUERRA, A.J.T. Novo Dicionário Geológico-Geomorfológico. Rio de Janeiro: Bertrand Brasil, 1997.

INFRAESTRUTURA NACIONAL DE DADOS ESPECIAIS. Mapa de Solos da Folha SB.24: Jaguaribe. Escala 1:250.000. Documento cartográfico em arquivo vetorial. Disponível em: 〈http://www.visualizador.inde.gov.br/>. 2014. Acesso em: 27 nov. 2015.

INSTITUTO BRASILEIRO DE GEOGRAFIA E ESTATÍSTICA. Ministério do Planejamento, Orçamento e Gestão. 2015. Malha municipal digital do Brasil: situação em 2015. Rio de Janeiro: IBGE. Disponível em <ftp://geoftp.ibge.gov.br/malhas_digitais/>. Acesso em: 10 abr. 2017.

MAINGUET, M. Le modele de grés: problèmes generaux. Tome I. e II. Paris: I.G.N, 1972. ISBN 9780470723715.

MARANGON, M. Universidade Federal de Juiz de Fora. Elementos de Geologia. Cap. 5. 2009. Disponível em <http://www.ufjf.br/nugeo/files/2009/11/Geologia-Cap5.pdf >. Acesso em: 19 mar. 2018.

MEDEIROS, S.C.O.; ASSIS, H.Y.E.G.; MENESES, L.F. Mapeamento da Geodiversidade do Município de Rio Tinto - PB. In: Congresso de Ecologia do Brasil, 10., 2011, São Lourenço, Anais... São Lourenço: 2011, p.1-2.

MEDEIROS, W.D.A.; OLIVEIRA, F.F.G. Geodiversidade, Geopatrimônio e Geoturismo em Currais Novos, NE do Brasil. Mercator, Fortaleza, v.10, n.23, p.59-69, set./dez. 2011. DOI: 10.4215/RM2011.1023.0005.

PEREIRA, P.J.S. Patrimônio geomorfológico: Conceptualização, avaliação e divulgação. Aplicação ao Parque Nacional de Montesinho. 2010. 317 f. Tese (Doutorado em Ciências Geológicas) - Universidade do Minho. Minho, 2006.

PEREIRA, J.M.; BRILHA, J.; GOMES. A.M. Proposta para a promoção do património geológico e da geoconservação na Conservação da Natureza de Cabo Verde. In: Congresso de Desenvolvimento Regional de Cabo Verde, 1; Congresso de Gestão e Conservação da Natureza, 3. Actas Proceedings... Cidade da Praia, Cabo Verde. 2009, p.3.195-3.210. ISBN 978-989-96353-0-2. 


\begin{tabular}{|c|c|c|}
\hline UFJ/UFG & $\begin{array}{c}\text { GEOAMBIENTE ON-LINE } \\
\text { Revista Eletrônica do Curso de Geografia } \\
\text { Graduação e Pós-Graduação } \\
\text { Htpp://www.revistas.ufg.br/geoambiente } \\
\text { Jataí-GO | n 36 | Jan-Abr/2020 }\end{array}$ & $\begin{array}{l}\text { :GEO } \\
\text { ISSN } 1679-9860 \\
\text { ISMBIENTE }\end{array}$ \\
\hline
\end{tabular}

PFALTZGRAFF, P.A.S.; TORRES, F.S.M. (Organização). Geodiversidade do estado do Rio Grande do Norte. Recife: CPRM, 2010.

PRODANOV, C.C.; FREITAS, E.C. Metodologia do trabalho científico: métodos e técnicas da pesquisa e do trabalho acadêmico. 2. ed. Novo Hamburgo: Feevale, 2013. ISBN 978-857717-158-3.

SANTOS, F. A.; LIMA, M. B. Geodiversidade e Geoturismo no Noroeste do município de Piracuruca (Piauí). Caderno de Geografia, v.28, n.54, 2018. DOI: 10.5752/P.23182962.2018v28n54p598-609.

SANTOS, J.C. Quadro geomorfológico do Parque Nacional de Sete Cidades, Piauí. 2011. 128 f. Dissertação (Mestrado em Geografia) - Universidade Federal de Santa Catarina. Florianópolis, 2001.

SEABRA, G.F. Turismo sertanejo, patrimônio e comunidades. In: PORTUGUE, A.P.; FREITAS, B.; OLIVEIRA, H.C.M. (Organizadores). Turismo sertanejo: a comunidade, o lugar e os saberes locais. Ituiutaba, Barlavento, 2014. p.9-16. ISBN: 978-85-68066-00-3.

SERVIÇO GEOLÓGICO DO BRASIL. Mapas estaduais de geodiversidade: Piauí. Rio de Janeiro: CPRM. 2006a. Documento cartográfico em arquivo vetorial. Disponível em <http://geobank.sa.cprm.gov.br>. Acesso em: 29 jan. 2018.

Mapa Geológico do Estado do Piauí. $2^{\text {a }}$ Versão. Teresina, 2006b.

STANLEY, M. Geodiversity. Earth Heritage, v.14, p.15-18. 2000. 